\title{
Pineapple Chicken Pizza
}

\section{Benjamin Jett}

1 cup of chopped pineapples

1 cup of pineapple juice

1 sliced green pepper and carrot

1 cup of pre-cooked sliced chicken

$1 \mathrm{lb}$. dough, homemade or store bought

Any additional veggies or toppings

1 cup of mozzarella cheese

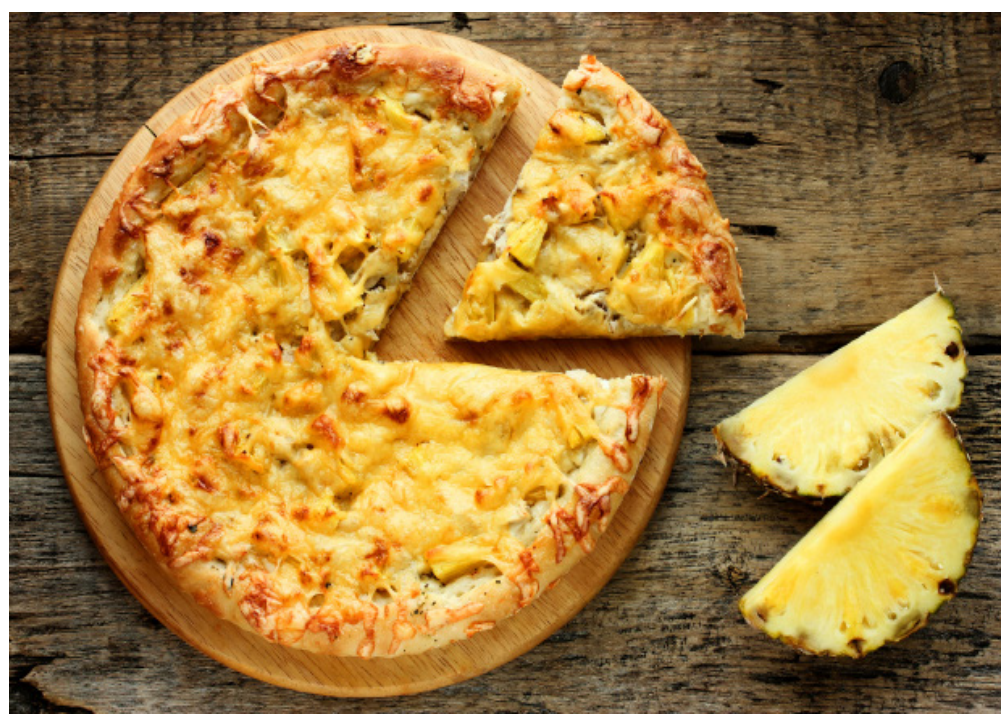

Description: Round pizza with pineapple with one slice on a wooden round board. Two slices of pineapple lay in the bottom right side.

This recipe is a pizza-fied version of a dish I personally love from my Filipino background, pininyahang manok. My mother makes this anytime I return home from school and it instills quite a bit of nostalgia about my own childhood. I love all of my mother's traditional Filipino dishes, but this one has to be my absolute favorite.

It starts with tenderizing the chicken and slicing it into bite size pieces, then marinating that in pineapple juice for about 30-45 minutes. Make sure to keep the juice for the sauce base while you sauté the pineapples and pineapple juice to give it a more viscous consistency. Then, cook the chicken until light brown. If you wish to add additional veggies, you can precook them after washing with the chicken. Roll the pizza dough while everything is cooking into a thin circle. Once everything is prepped and cooked, spread the pineapple base evenly on the dough and then sprinkle on the mozzarella. Then, add the chicken, pineapple slices, green pepper, and any additional toppings to preference. Preheat the oven to $475^{\circ} \mathrm{F}$, then let pizza bake from 10-15 minutes or until the cheese is golden and the crust brown.

Serve and enjoy! 